\title{
What may a fussy creature reveal about body/cell size integration under stressful conditions?
}

\author{
Aleksandra Walczyńska ${ }^{1}$ (D) Anna Maria Labecka ${ }^{1} \cdot$ Mateusz Sobczyk $^{1}$
}

Received: 16 July 2017 / Accepted: 23 April 2018 / Published online: 4 May 2018

(C) The Author(s) 2018

\begin{abstract}
There is a growing amount of empirical evidence on the important role of cell size in body size adjustment in ambient or changing conditions. Though the adaptive significance of their correspondence is well understood and demonstrated, the proximate mechanisms are still in a phase of speculation. We made interesting observations on body/cell size adjustment under stressful conditions during an experiment designed for another purpose. We found that the strength of the body/cell size match is condition-dependent. Specifically, it is stronger under more stressful conditions, and it changes depending on exposure to lower temperature vs. exposure to higher temperature. The question whether these observations are of limiting or adaptive character remains open; yet, according to our results, both versions are possible but may differ in response to stress caused by too low vs. too high temperatures. Our results suggest that testing the hypotheses on body/cell size match may be a promising study system for the recent scientific dispute on the evolutionary meaning of developmental noise as opposed to phenotypic plasticity.
\end{abstract}

Keywords Body size $\cdot$ Cell size $\cdot$ Proximate mechanisms $\cdot$ Stressful conditions $\cdot$ Temperature $\cdot$ Communicated by Dr. Nico Posnien

\section{Introduction}

We based our study on the hypothesis that body size decreases with increasing temperature, an observation named the temperature-size rule (TSR; Atkinson 1994). It was proposed that this phenomenon is a consequence of a decrease in cell size as an adaptation to limited oxygen availability at high temperatures (Atkinson et al. 2006; Czarnoleski et al. 2015; Verberk et al. 2011; Walczyńska et al. 2015a; Woods 1999). The proximate mechanism of cell size adjustment is based on changes in the amount or structure of DNA within a cell (Czarnoleski et al. 2017; Hessen 2015; Hessen and Persson 2009; Jalal et al. 2015; Jalal et al. 2013; Kozłowski et al. 2003). DNA is mostly known from its coding and regulatory functions, but another field of knowledge is its effect on cell parameters (Gregory and Hebert 1999). This role of DNA

\section{Communicated by Nico Posnien}

Aleksandra Walczyńska

aleksandra.walczynska@uj.edu.pl

1 Institute of Environmental Sciences, Jagiellonian University, Gronostajowa 7, 30-387 Krakow, Poland further affects the organism body size (though not in homeotherms; Hessen 2015) and therefore has potentially substantial effects on fitness (Gregory and Hebert 1999; Gregory et al. 2000; Hessen 2015). The interrelationships between genome size, cell volume, and body size can be realized by several possible mechanisms (Cavalier-Smith 1978; Gregory et al. 2000). Curiously, the widely accepted ecological consequences of these relationships are now better understood than their proximate mechanisms (Hessen 2015; Hessen et al. 2013; Hessen and Persson 2009; Kozłowski et al. 2003).

In this study, we analyze and discuss some interesting results on body/cell size adjustment under stressful conditions observed during an experiment designed for another purpose. We repeated the experiment using a non-eutelic annelid Aeolosoma hemprichi Ehrenberg 1828 on the body size effect on the population growth under low/high-temperature/oxygen conditions, which we have previously conducted on an eutelic rotifer Lecane inermis Bryce, 1892 (Walczyńska et al. 2015a). Both L. inermis (Kiełbasa et al. 2014; Walczyńska et al. 2016) and A. hemprichi (Walczyńska et al. 2016) were previously reported as decreasing in size with increasing temperature, following the TSR, while exposed to wide temperature range. In both a previous study on rotifers and in the current study on A. hemprichi, we performed a two-step study: in the first step, 
we aimed at differentiating the organisms' body size by culturing them at different temperatures, while in the second stage, we examined the fitness (fecundity in rotifers and population growth rate in annelids) of the second generation of "small" and "large" individuals at combinations of low and high levels of two factors, temperature and oxygen (Fig. 1). We then related the body size changes to cell size (nucleus size in the rotifer case). In our previous study on L. inermis, we found support for all the hypotheses posed: body size was found to be an adaptation to temperature-dependent oxygen availability, realized through cell size adjustment (Walczyńska et al. 2015a). A. hemprichi appeared to be sensitive in the laboratory conditions. Due to failures at the second experimental stage, we repeated the entire experiment. Even with that, our goals were not achieved because the $A$. hemprichi population did not proliferate well in experimental treatments. However, we explored our results from the perspective of the relationship between body size and cell size under stressful conditions. We present some novel ideas regarding the match between cell and body size and its limitations.

\section{Methods}

\section{Study species}

Aeolosoma hemprichi is a 500-1500- $\mu$ m-long (Menniti and Morgenroth 2010) limnetic annelid, which reproduces by paratomic fission (Falconi et al. 2006). It is a stenophagous bacterivore (Inamori et al. 1990; Ratsak and Verkuijlen 2006; Suzuki et al. 2005). The study was conducted on the A. hemprichi clone isolated from the activated sludge in a small wastewater treatment plant in southern Poland. Prior to this study, A. hemprichi was cultured at room temperature (ca. $21{ }^{\circ} \mathrm{C}$ ) and natural photoperiod, without oxygen manipulation. Different sources of biofilm were tested (rice, buckwheat, and molasses), and the annelid proliferated equally well on each of them.

\section{Experimental design}

In the first experimental stage (hereafter, step I), we aimed to induce the divergence in body size toward "small" and "large." We cultured them in 300-mL glass containers (approximate final density of 100-200 individuals per container) with spring water (Żywiec, Poland) as a medium and three rice seeds as a biofilm source and placed them in the water baths (Memmert, Germany) set to $18,21,24$, or $27^{\circ} \mathrm{C}$ (three replicates per treatment).

In the second experimental stage (hereafter, step II), animals were exposed to four different treatments with a combination of low/high-temperature and low/high-oxygen concentration (Fig. 1). We used small plastic 5-mL tubes closed with

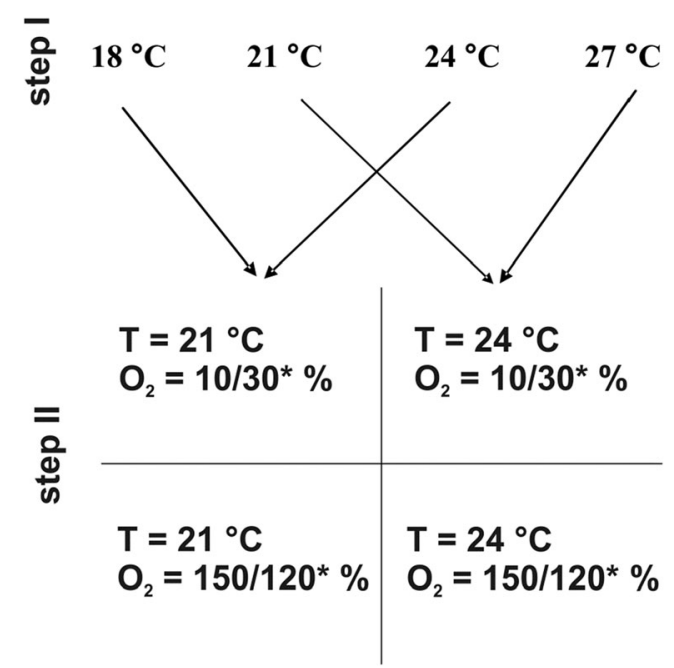

Fig. 1 The scheme of the experiment. In step I, annelids were differentiated in body size by exposure to four different temperatures. In step II, each "size group" was placed in a combination of low/hightemperature/oxygen conditions so that the temperature change was smaller or larger by always the same amount $\left(3{ }^{\circ} \mathrm{C}\right.$ in this case). $*$ The notation means the oxygen concentration in trial $1 /$ trial 2

nylon mesh on both ends immersed in water baths for that purpose. We started step II with 20 individuals of a similar medium size per replicate (three replicates per treatment). Animals were provided with the same medium and food type as in step I. To generate the experimental oxygen conditions, we used an Oxy-Reg four-channel $\mathrm{O}_{2}$ regulation system (Loligo Systems, Denmark). The system was calibrated for 0 and $100 \%$ of air-saturated water. Because of the problems with little animal proliferation in this second stage of the study in the first trial (trial 1), the study was repeated (trial 2). In trial 1, the step II experiment was conducted under a temperature of 21 or $24{ }^{\circ} \mathrm{C}$ and oxygen concentration of 10 or $150 \%$ (Fig. 1). The numbers of $A$. hemprichi decreased in all but one replicate after 4 days. In trial 2, the only difference in experimental design was that we narrowed the range of oxygen conditions to 30 and $120 \%$ to possibly increase the annelid survival. However, the numbers of individuals did not generally increase above the initial value after 8 days of the experiment. We decided to analyze the samples from trial 2 treating the body and cell size as a response to stressful experimental conditions. The annelid number analyses were conducted for trial 1 and trial 2 separately.

\section{Cell and body size measurements}

For the measurements of cell size and body size response to temperature (step I) and to temperature-oxygen conditions (step II), annelid samples were taken from trial 2 only. The annelids were fixed in $10 \%$ buffered neutral formalin $(\mathrm{POCH}$, Poland). Afterward, $1 \mathrm{ml}$ of $1 \times$ phosphate-buffered saline (PBS; POCH) was added, and the samples were centrifuged (2000 rpm, 2 min; Eppendorf 5702, Germany). The 
supernatant was replaced by fresh $1 \times$ PBS five times, and the centrifugation step was also repeated five times. Then, $1 \times$ PBS was extracted and replaced with $0.5 \mathrm{~mL}$ of Gill's hematoxylin (Carl Roth, Germany). The animals were stained with hematoxylin for $4 \mathrm{~h}$ at room temperature and centrifuged. The A. hemprichi precipitate was dropped onto a glass slide and photographed under an Eclipse 80i light microscope (Nikon) equipped with an Axio CamMRc5 digital camera (Zeiss, Germany) and ZEN (Zeiss) software. The white adipocytes (unilocular cells) were chosen for cell measurements because they were the only cell type clearly visible throughout all of the animal samples. Generally, the lipid storage mechanisms in invertebrates function similarly to these of vertebrates (Azeez et al. 2014; Schlegel and Stainier 2007). The processes within adipocytes are dependent not exclusively on the amount of food but are also affected by the hormones they produce and by the nervous system (Young et al. 2006). It makes these cells possibly highly responsive to stress. They may also respond to temperature; white adipocytes in mice were found to activate thermogenesis when exposed to lower temperatures (Ye et al. 2013). Pictures of the slides were examined using ImageJ software (NIH, USA). To estimate body size, we measured perimeter as a proxy for body area $\left(\mu \mathrm{m}^{2}\right)$. To assess the size of the adipocyte cells $\left(\mu \mathrm{m}^{2}\right)$, we measured two perpendicular diameters of 10 cells per animal, collected from three to five photos of different body parts of the same individual. In the cases when measuring 10 cells per animal was not possible, at least five cells were measured. In two exceptional cases, only three and in one case, four cells per specimen were measured. The example of annelids and adipocytes in annelids used for measurements is presented in Fig. 2.

\section{Statistical analysis}

The numbers of individuals surviving to the end of step II were analyzed with GLM for trial 1 and trial 2 separately, with temperature, oxygen concentration, and experienced direction of temperature change (two groups: experiencing temperature decrease (hereafter, Temp-) or increase (hereafter, Temp+) in comparison with conditions in step I) as fixed factors. The temperature effects on body size and cell size in step 1 of trial 2 only were analyzed with the Kruskal-Wallis test (an assumption on the homogeneity of variance for ANOVA was not met in the case of body size, and an assumption on the normality of residuals was not met for cell size data). Body and cell size differences in step II of trial 2 were analyzed using either ANOVA with temperature and experienced direction of temperature change as fixed factors, or ANCOVA, using cell size as a covariate. The model was tested for the possible significance of the interactions between the main factors and a covariate to check whether the assumption on the similar slope of the relationship between the dependent variable and a

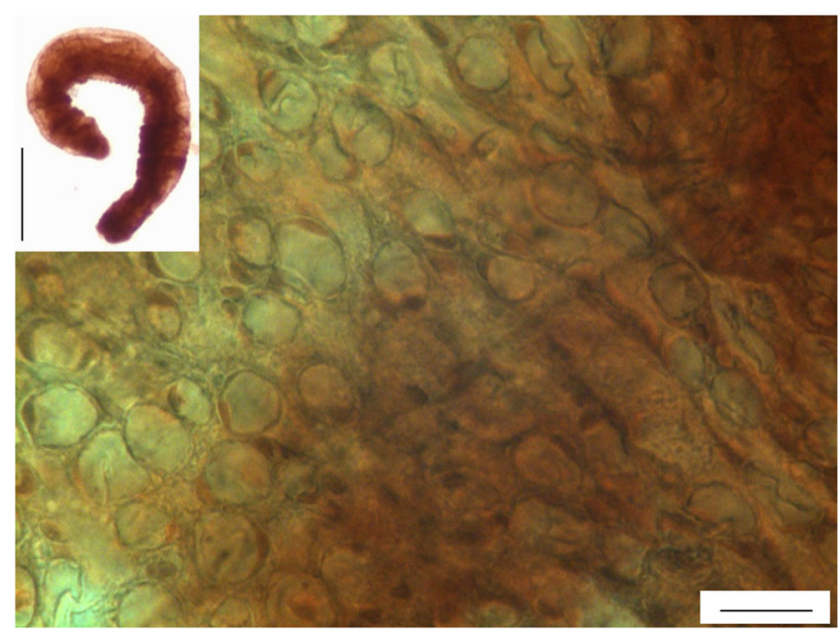

Fig. 2 The illustration of research material used for body and cell size measurements in A. hemprichi. Scale bar for an annelid, $200 \mu \mathrm{m}$, and scale bar for white adipocytes, $10 \mu \mathrm{m}$

covariate across treatments was not violated. The relationship between body size and cell size, for both step I and step II in trial 2, were analyzed using simple regression. All the analyses were performed in Statistica 12 (StatSoft 2014).

\section{Results and discussion}

\section{The effect of conditions in step II on annelid number in trials 1 and 2}

A new interesting observation was a significant effect of the experienced direction of temperature change, whether deriving from the low temperature in step I and experiencing the temperature increase in step II (Temp+) or deriving from the high temperature in step I and experiencing the temperature decrease in step II (Temp-). In trial 1, Temp+ annelids performed significantly better than Temp- annelids (Table 1 and Fig. 3). In trial 2, there was no difference in performance between these two groups, but this effect might have been masked by the significant interaction of temperature, oxygen, and experienced direction of temperature change in this trial (Table 1 and Fig. 3). Generally, the response of Temp+ and Temp- annelids differed despite them not differing in size in step I.

There was no effect of temperature on the number of annelids, while the effect of oxygen was significant, and yet, the direction of response toward low or high oxygen levels differed between trials (Table 1). In trial 1 , the annelids performed better at a higher $(150 \%)$ rather than at a lower $(10 \%)$ oxygen level, especially at higher temperature (Fig. 3 ). Annelids performed extremely poorly at a high oxygen level $(120 \%)$ and were in relatively good condition at a lowoxygen treatment (30\%; Fig. 3) in trial 2. The most likely reason for such a difference was the presence of unidentified 
Table 1 The results of GLM analysis on number of individuals of A. hemprichi observed after the completion of step II in trials 1 and 2
Factors
SS
df
$\mathbf{F}$
p

\begin{tabular}{lcccc}
\hline Trial 1 & & & & \\
Temperature & 9.38 & 1 & 0.646 & 0.432 \\
Oxygen & 315.38 & 1 & 21.727 & 0.0002 \\
Temp+/Temp- & 176.04 & 1 & 12.128 & 0.0025 \\
Temperature $\times$ Temp+/Temp- & 135.38 & 1 & 9.326 & 0.0065
\end{tabular}

\section{Trial 2}

Temperature

Oxygen

Temp+/Temp-

Temperature $\times$ Temp $+/$ Temp-

Temperature $\times$ Oxygen $\times$ Temp $+/$ Temp-
66.67

1

2.755

0.1142

770.67

1

31.853

0.0002

0.17

1

0.007

0.9348

96.00

1

3.968

0.0618

121.50

1

5.022

0.0379

All of the non-significant interactions were removed from the models. Temp+/Temp- denotes individuals deriving from the lower temperature in step I and experiencing temperature increase in step II/deriving from the higher temperature and experiencing temperature decrease in step II. Significant effects are marked in red

filamentous microorganisms (Fig. 4), which infected the samples at the $120 \% \mathrm{O}_{2}$ treatment in trial 2. The means in which the filaments could have affected the annelids remain uncertain. The identification of these microorganisms, whether of bacterial or fungal origin, would shed more light on this issue; we assume that bacteria could have deprived the annelids of food (filamentous bacteria, not accessible to annelids, could outcompete other bacteria), while the possible effect of fungi on $A$. hemprichi could be the movement disturbance. The generally low numbers of individuals counted after the completion of trials 1 and 2 show the considerable sensitivity of A. hemprichi to experimental conditions. These problems were apparently caused by the sensitivity to rapid changes in temperature/oxygen conditions because annelids proliferated successfully both in a laboratory culture on various substrates and in step I of this study.

The appearance of the unknown filamentous contamination in the $120 \%$ oxygen treatment in trial 2 prevented us from

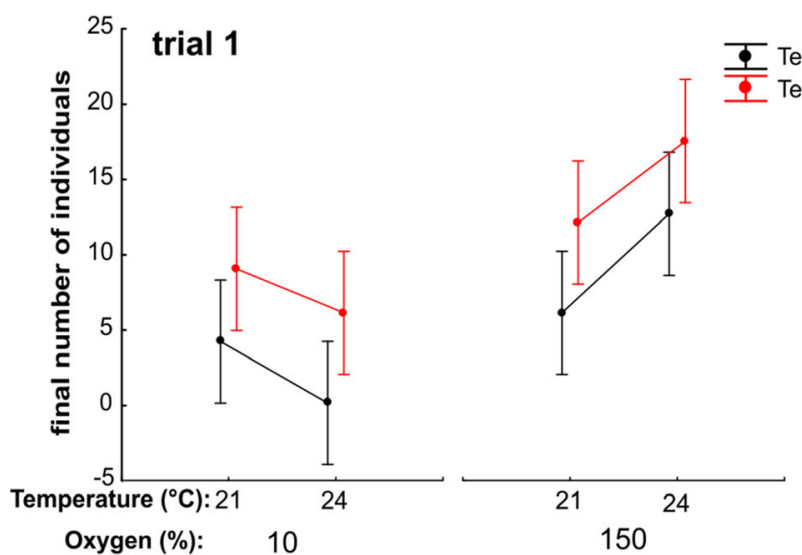

Fig. 3 The three-level interaction effect on A. hemprichi numbers after the completion of step II of trial 1 (not significant) and trial 2 (significant). LS means \pm 0.95 CI for the three replicates. Temp- are individuals

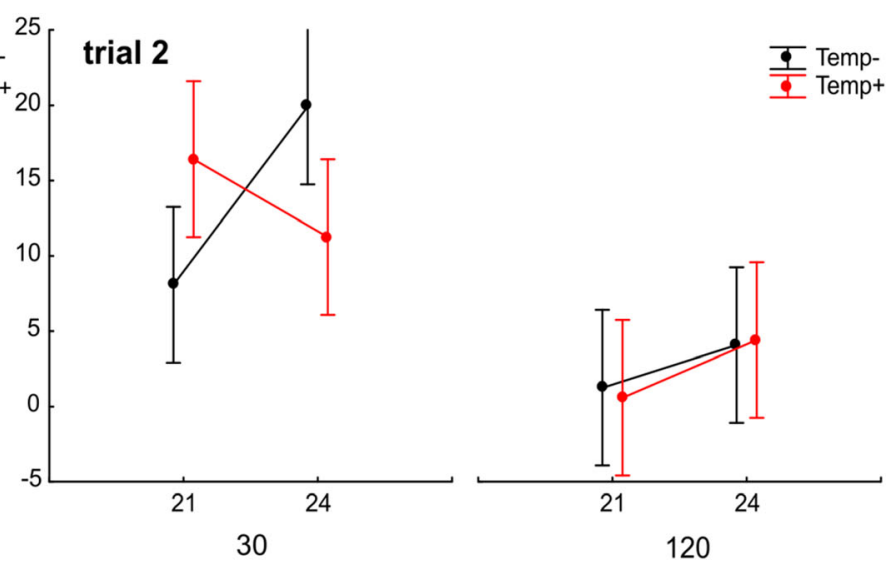

experiencing temperature decrease in step II; Temp+ are individuals experiencing temperature increase in step II compared to conditions in step I 


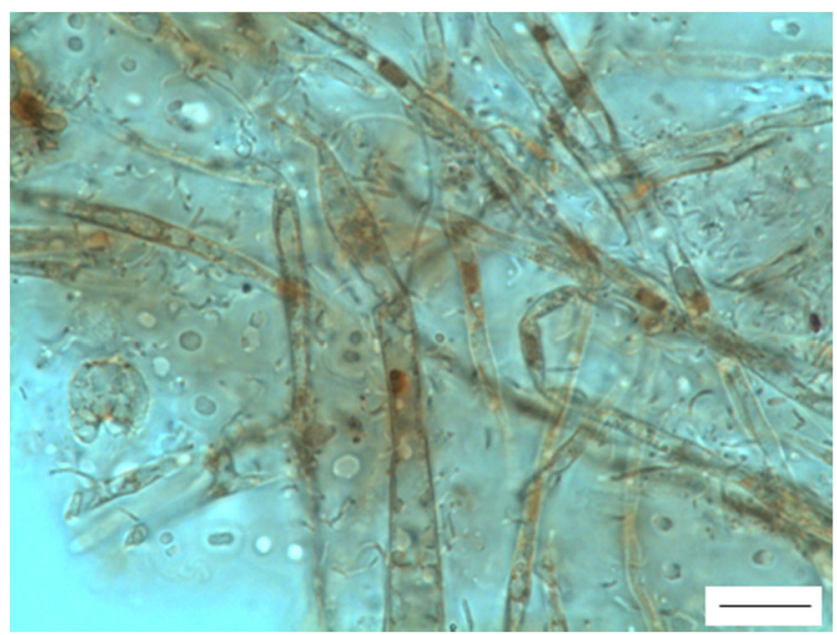

Fig. 4 The unidentified filaments most likely disturbing the proliferation of annelids in the high oxygen concentration treatment (120\%) of step II of trial 2

obtaining unambiguous conclusions on the effect of oxygen on A. hemprichi. However, by comparing trials 1 and 2, we may speculate that $A$. hemprichi is sensitive to very low oxygen levels ( $10 \%$ in trial 1$)$ and performs similarly well in 30 and $150 \% \mathrm{O}_{2}$. The only difference between these two treatments was the poor proliferation of Temp+ annelids at $24{ }^{\circ} \mathrm{C}$ under $30 \% \mathrm{O}_{2}$ compared to $150 \% \mathrm{O}_{2}$ (Fig. 3). This result has important implications: the temperature of $24{ }^{\circ} \mathrm{C}$ is above the optimum regarding $A$. hemprichi performance measured to be $21{ }^{\circ} \mathrm{C}$ by Walczyńska et al. (2016), but such conditions seem to be limiting only under hypoxia and not hyperoxia. The joint limiting conditions of high temperature and hypoxia were previously observed during examination of fecundity in the L. inermis rotifer (Walczyńska et al. 2015a). From the perspective of the global warming issue, both the previous and current results validate the suggestion that it is not temperature itself, but rather its relationship with oxygen relative concentration, that matters as a factor responsible for size response (Atkinson et al. 2006; Walczyńska and Sobczyk 2017).

\section{The effect of temperature on body and cell size in step I of trial 2}

The mean coefficient of variation (CV) for cell size measured within a specimen for individuals deriving from 18, 21, 24, and $27^{\circ} \mathrm{C}$ were $26.2 \%(N=24), 29.3 \%(N=30), 24.8 \%(N=$ $21)$, and $27.5 \%(N=49)$, respectively. The relatively high variability of adipocyte size within an animal may result from the fact that they were measured from three to five photos representing different parts of the body, while this cell type shows considerable size variability in general (Sawicki and Malejczyk 2012, for the case of humans). Yet, our approach made the results representative for an individual.

Body size did not differ across treatments (Kruskal-Wallis $H_{(3,131)}=6.75, p=0.0803$ ), while cell size differed (Kruskal-
Wallis $\left.H_{(3,124)}=21.64, p=0.0001\right)$; cells of annelids from $21{ }^{\circ} \mathrm{C}$ were significantly smaller than those from 24 and $27{ }^{\circ} \mathrm{C}$. In light of the previous studies on A. hemprichi body size response to temperature, the lack of differences in body size obtained in the present study might be caused by the chosen thermal range, which was too close to the approximate optimal value, estimated to be $21{ }^{\circ} \mathrm{C}$ (Walczyńska et al. 2016). Body size significantly depended on cell size $(N=124, p=$ $0.0012, r^{2}=0.0823$; Fig. 5 , upper panel) for the data pooled for all thermal regimes.

\section{The effect of experimental conditions on body and cell size in step II of trial 2}

After excluding the samples from $120 \% \mathrm{O}_{2}$ infected by filaments, the results show no effect of temperature but a significant effect of the experienced direction of temperature change (Temp+/Temp-) on body size (Table 2 and Fig. 6a). Qualitatively similar results were obtained for cell size (Table 2). A mean CV for cell size measured within a specimen for individuals deriving from treatments Temp $+/ 21 / 30$, Temp+/24/30, Temp- $/ 21 / 30$, and Temp- $/ 24 / 30$ were $24.5 \%$ $(N=8), 35 \%(N=22), 16 \%(N=3)$, and $22.6 \%(N=8)$, respectively. Interestingly, including cell size as a covariate in the model for body size differences resulted in an observation that initial conditions did not have a significant effect on cell size (Table 2 and Fig. 6b); the annelids exposed to lower experimental temperature (Temp-) were not larger than Temp+ when the size of their cells was taken into consideration (Fig. 6). We explore the important consequences of this result below. Body size was significantly dependent on cell size for the data pooled for all experimental treatments $(N=$ $41, p=0.0001, r^{2}=0.3190$; Fig. 5, lower panel).

Our results inspired us to reflect more broadly on the general relationship between the cell and body size adjustment under stressful conditions. We now invoke some possible points for discussion.

\section{To what extent do cell size and body size correspond?}

We found that the relationship between body size and cell size is stronger in the stressful conditions maintained during step II than in step I (Fig. 5) despite the much smaller sample size. We compared this result with the data from the experiment previously conducted on rotifers (Walczyńska et al. 2015a). In that case, the difference was even more pronounced; in step I, the relationship between the individual body and nucleus size of rotifers was not significant $\left(N=101, p=0.6330, r^{2}=\right.$ 0.0023 ), while this relationship analyzed using the data from step II was significant $\left(N=113, p=0.0110, r^{2}=0.0568\right.$; Fig. 7). Thus, it suggests that under mild conditions, the body/cell size match is relaxed while its strict adjustment switches on under more stressful (= physiologically 
Fig. 5 The relationship between body size and cell size in A. hemprichi in step I (upper panel) and step II (lower panel) conditions (trial 2). Different treatments are marked with different symbol colors
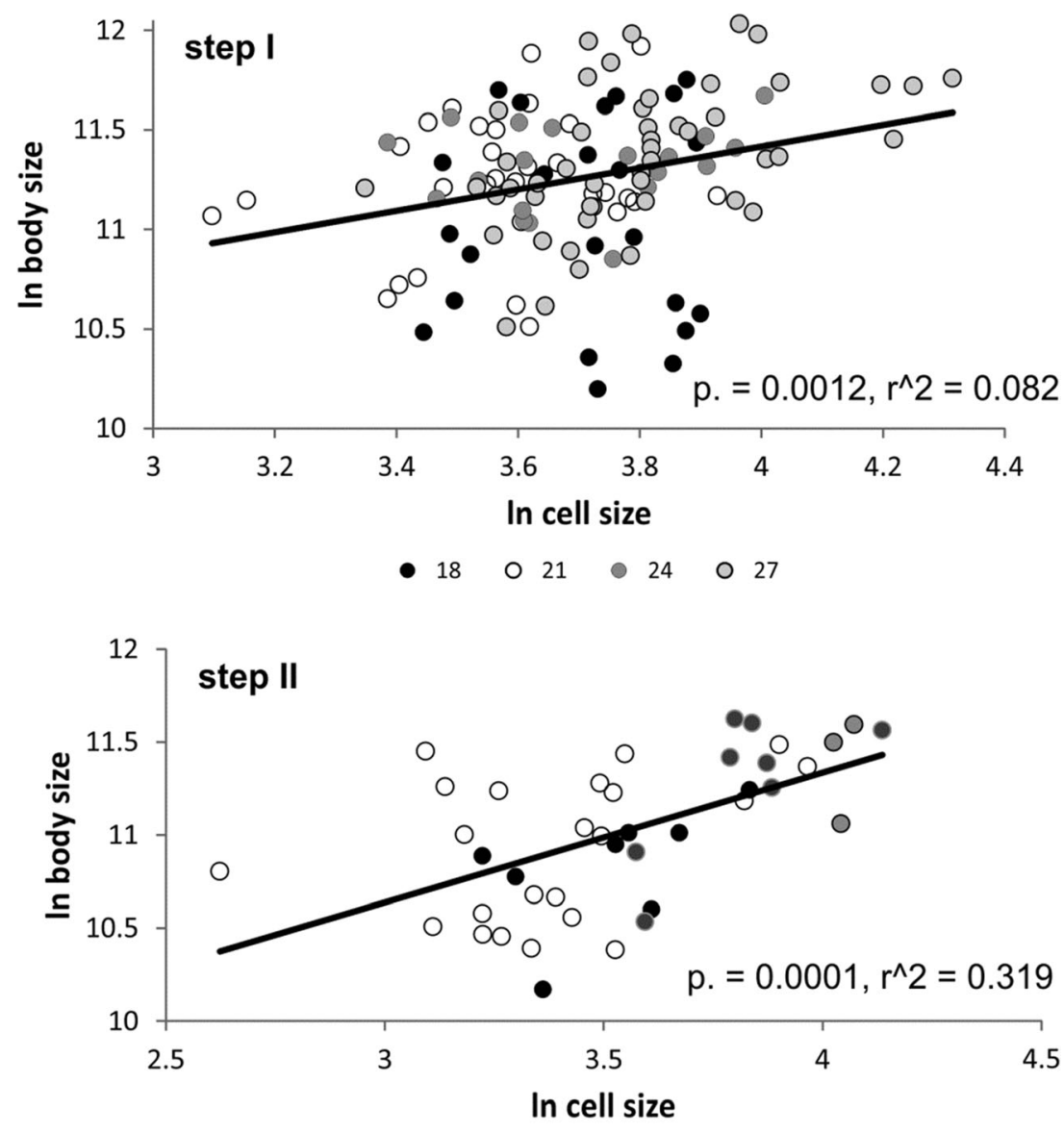

- TI_21_30 O TD_21_30 - TD_24_30 O TI_24_30

Table 2 The results of GLM analysis on body and cell size of A. hemprichi after step II of trial 2

\begin{tabular}{lllll}
\hline \multicolumn{1}{c}{ Factors } & SS & df & F & p \\
\hline In body size - ANOVA & & & & \\
Temperature & 0.02 & 1 & 0.120 & 0.728 \\
Temp+/Temp- & 1.36 & 1 & 10.01 & 0.003 \\
In cell size - ANOVA & & & & \\
Temperature & 0.20 & 1 & 3.314 & 0.076 \\
Temp+/Temp- & 1.70 & 1 & 27.571 & $<0.001$ \\
In body size - ANCOVA & & 1 & & 0.237 \\
Temperature & 0.16 & 1 & 1.443 & 0.468 \\
Temp+/Temp- & 0.06 & 1 & 0.537 & 0.006 \\
In cell size & 0.98 & 1 & 8.653 & \\
\hline
\end{tabular}

Significant effects are marked in red. Temp+ are individuals experiencing temperature increase in step II, and Temp- are individuals experiencing temperature decrease in step II, compared to conditions in step I 

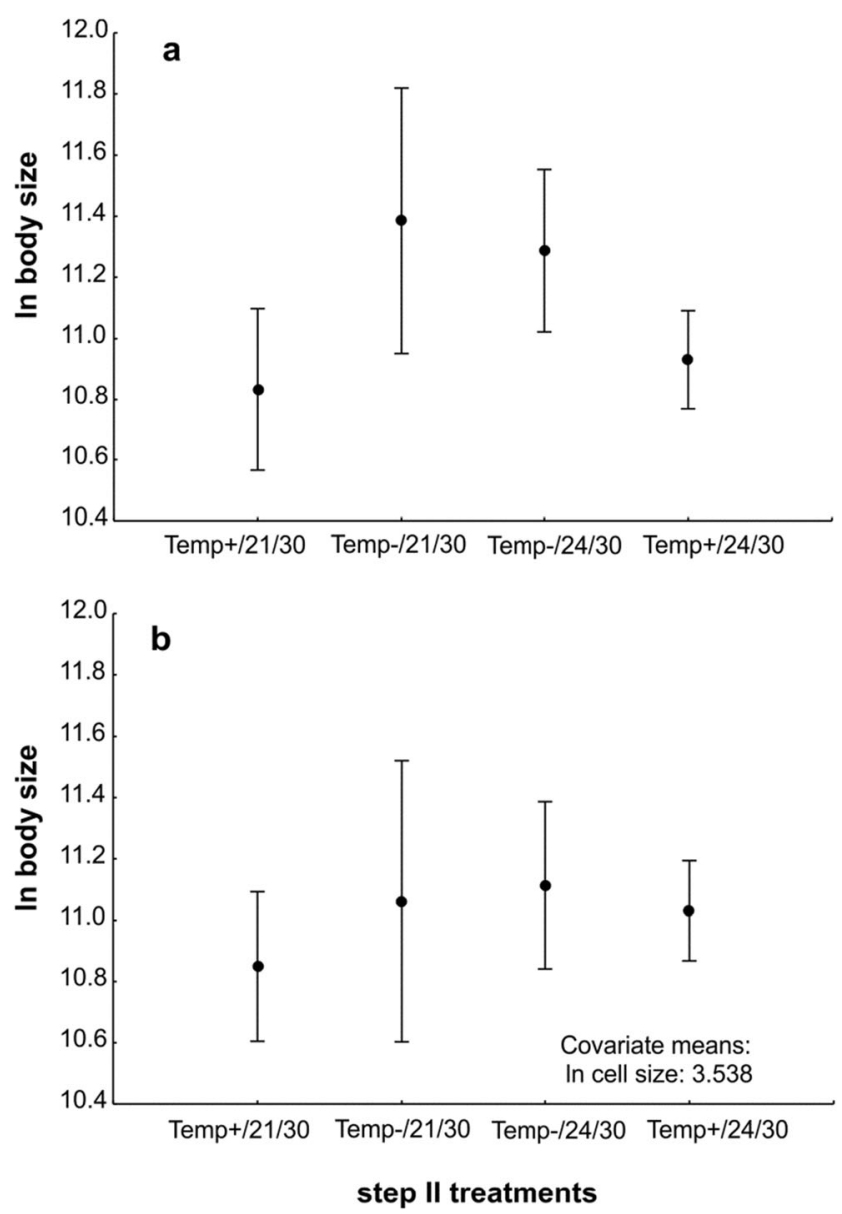

Fig. 6 The difference in body size of A. hemprichi in step II treatments after simple ANOVA (a) and after ANCOVA with cell size as a covariate (b). Means \pm CI. The treatment code is as follows: experienced direction of temperature change/temperature/oxygen. Temp- are individuals experiencing temperature decrease in step II; Temp+ are individuals experiencing temperature increase in step II, compared to conditions in step I

demanding) conditions. To our knowledge, this is the first observation of the condition-dependent strength of the body/ cell size adjustment. Additionally, our results show that similar mechanisms of response to stressful conditions are launched in exemplary eutelic (previous study; rotifers) and non-eutelic (this study; annelids) organisms, which may indicate the superordinate role of cell size over cell number in overcoming harsh temperature/oxygen conditions.

A very subtle and interesting aspect of the body/cell size adjustment in our study is that the effect of a larger body size in the Temp- group in trial 2 diminished after including cell size as a covariate in a model (Fig. 6). This intriguing result confirms the condition-dependent strength of body/cell size correspondence, in this case related to temperature increase vs. decrease. For practical use, this observation also shows that the body/cell size relationship should be taken into account in any laboratory study when a body size response to a given variable is to be evaluated.
An indirect confirmation of the importance of the correspondence between the cell and body size in response to temperature may be found in the report by Jalal et al. (2015). The authors focused on different aspects of the interrelationship between genome, cell, and body size in Drosophila melanogaster. They found, among others, that the level of DNA condensation decreased with increasing temperature according to the general models, but only in the case of the whole organisms, while the pattern was opposite for the cell cultures. Thus, the response of Drosophila cells from the cell culture differed from the cell response in the whole Drosophila organism, possibly because of some superordinate orders from the higher levels of body organization in the latter case. This may be associated with the so-called "supracellular service," a term raised, for example, in the case of the BMR response in different tissues of mice (Maciak et al. 2014) or the microtubular response to mechanical stress in Arabidopsis thaliana (Jacques et al. 2013).

\section{What is the difference in proximate mechanisms behind the response to increasing and decreasing temperature?}

The pattern of the importance of the experienced direction of temperature change of individuals, whether experiencing lower (Temp-) or higher (Temp+) temperature, was observed regardless the fact that both "Temp+" and "Temp -" groups actually consisted of annelids deriving from two different temperatures in step I (18 and 21 vs. 24 and $27{ }^{\circ} \mathrm{C}$, respectively; Fig. 1) and regardless of the lack of differences in size between annelids in these groups. This finding means that the cue toward the direction of temperature change may be more important for ectotherms than the temperature itself. Such a result was previously suggested in a study on the TSR determination in $L$. inermis rotifers (Walczyńska et al. 2015b). Two explanatory mechanisms behind different body/cell size matches in Temp-/Temp+ annelids, as illustrated in Fig. 6, are possible:

H1-A cue of temperature increase acts differently on body/cell size adjustment than a cue of temperature decrease, a constraint, or

H2 - Under stressful conditions, the ratio of body size to cell size is optimized or canalized (sensu Waddington 1942), an adaptation.

Neither of these hypotheses can be tested here because of the small sample size per experimental treatment. However, some light may be shed by the pattern of population numbers in respective groups (trial $2 ; 30 \% \mathrm{O}_{2}$ in Fig. 3). It is clear that the demarcation line for fitness does not go through the Temp-/Temp+ treatment but through a combination of this factor interacting with the temperature/ 
Fig. 7 The relationship between body size and cell size in L. inermis in step I (upper panel) and step II (lower panel) conditions (unpublished data; methodology described in Walczyńska et al. 2015a). Different treatments are marked with different symbol colors

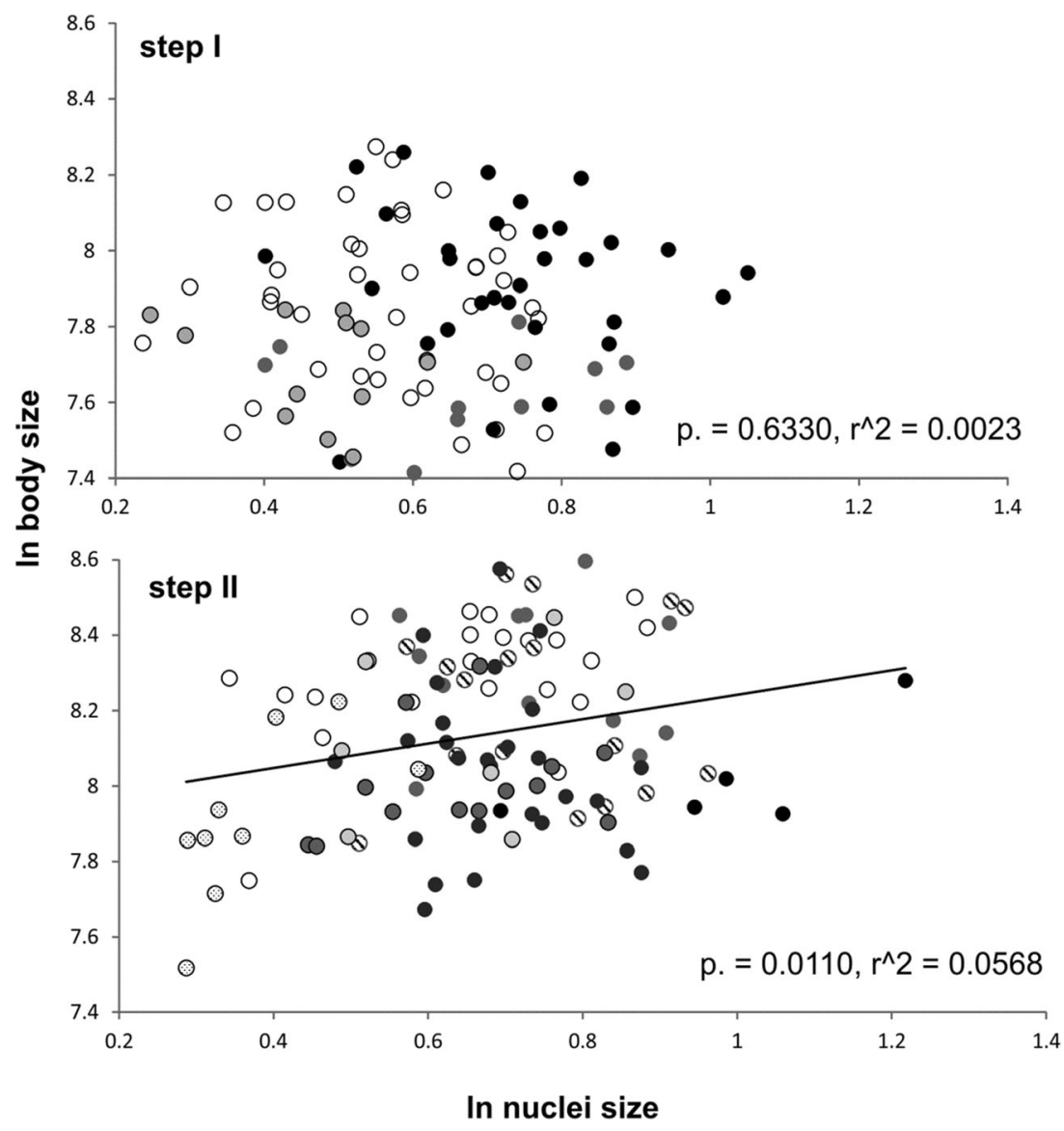

oxygen combination, which would signify the limiting, rather than adaptive, meaning of different body/cell size match in Temp- vs. Temp+ annelids. On the other hand, another one of our results shows that the body/cell size match is stronger in stressful than in mild conditions, regardless of the experimental treatment (Fig. 5), and favors the adaptive meaning. We will refer to this issue below.

The study on the effect of temperature on the structural changes in the genome and their further consequences for cell and body size in ectotherms, conducted by Jalal et al. (2013) on Daphnia, may act as an indirect confirmation of H1. The authors found that in the reversal experiment, DNA in the cells of Daphnia from $20^{\circ} \mathrm{C}$ and incubated at $10{ }^{\circ} \mathrm{C}$ showed a considerable decrease in both DNA content and its variation in the cells, while no reverse change was observed in the cells of Daphnia from $10{ }^{\circ} \mathrm{C}$ and incubated at $20^{\circ} \mathrm{C}$. This result could mean that only a cue toward temperature decrease launched a response in DNA content. In the case of Daphnia magna, the optimal temperature is approximately $26-28{ }^{\circ} \mathrm{C}$ (Lampert 2006). Therefore, $10^{\circ} \mathrm{C}$ seems to be suboptimal for this species. It would be interesting to show how this increasing variation in DNA content is reflected in body size, or whether this higher variation at a more stressful temperature is associated with a stronger link between cell size and body size.

\section{What is limiting and what is adaptive in the cell and body size relationship?}

It was proposed that cells (Czarnoleski et al. 2015; Kozłowski et al. 2003; Szarski 1983; Woods 1999) and bodies (Kozłowski et al. 2004; Kozłowski et al. 2003) decrease in size with increasing temperature. On the other hand, Hessen et al. (2013) proposed the interesting bottom-up perspective, in which the link between genome size and body size is driven by the genome size increase at low temperature, caused by the limitation in enzyme kinetics (Xia 1995) or in the efficiency of protein synthesis (Woods et al. 2003) at lower temperature. From the perspective of our results, these options are not mutually exclusive; it is possible that a temperature increase limits the oxygen transport efficiency, launching the cell size decrease through relevant changes in DNA structure, while a temperature decrease limits the proper genome maintenance, forcing the increase in the amount of DNA, followed by an increase in cell (and body) size. Further tests would demand studies on the genome, cell, and body size response to temperature, changing to both directions and conducted under optimal (mild) and suboptimal (stressful) conditions. The relatively well-known taxon regarding this matter is a widely studied group of crustaceans. For the case of amphipods, it was suggested that larger genomes may be associated with 
stable environments (Rees et al. 2007). Additionally, the study in Lake Baikal showed that genome size coevolved in this group of animals with body size in response to the selection to different habitats (= lake depth), but what the target of selection was (genome or body) remains unclear (Jeffery et al. 2017). Finally, climate conditions affect the body size composition in the case of both calanoid (Leinaas et al. 2016) and cyclopoid copepods (Rasch and Wyngaard 2006). In the latter case, a small genome size was suggested to be favored in stressful habitats (Rasch and Wyngaard 2006).

Recently, a stimulating discussion has been opened in the literature regarding the distinction between developmental noise and phenotypic plasticity and their consequence for evolution (Ghalambor et al. 2015; Woods 2014; Woods and Wilson 2015). The issue of body/cell size match under stressful conditions seems to be a promising study system for hypothesis testing.

Acknowledgments The authors thank Elżbieta Dumnicka for the species identification and Terézia Horváthová and two anonymous reviewers for the helpful comments on previous versions of this manuscript. The manuscript was edited by American Journal Experts. The study was funded by the Foundation for Polish Science (POMOST/2011-3/12) and by Jagiellonian University (DS/INoŚ/757/2017).

Open Access This article is distributed under the terms of the Creative Commons Attribution 4.0 International License (http:// creativecommons.org/licenses/by/4.0/), which permits unrestricted use, distribution, and reproduction in any medium, provided you give appropriate credit to the original author(s) and the source, provide a link to the Creative Commons license, and indicate if changes were made.

\section{References}

Atkinson D (1994) Temperature and organism size — a biological law for ectotherms. Adv Ecol Res 25:1-58

Atkinson D, Morley SA, Hughes RN (2006) From cells to colonies: at what levels of body organization does the "temperature-size rule" apply? Evol Dev 8:202-214. https://doi.org/10.1111/j.1525-142X. 2006.00090.x

Azeez OI, Meintjes R, Chamunorwa JP (2014) Fat body, fat pad and adipose tissues in invertebrates and vertebrates: the nexus. Lipids Health Dis 13:71. https://doi.org/10.1186/1476-511x-13-71

Cavalier-Smith T (1978) Nuclear volume control by nucleoskeletal DNA, selection for cell volume and cell growth rate, and the solution of the DNA C-value paradox. J Cell Sci 34:247-278

Czarnoleski M, Dragosz-Kluska D, Angilletta Jr MJ (2015) Flies developed smaller cells when temperature fluctuated more frequently. J Therm Biol 54:106-110

Czarnoleski M, Labecka AM, Starostová Z, Sikorska A, BondaOstaszewska E, Woch K, Kubička L, Kratochvíl L, Kozlowski J (2017) Not all cells are equal: effects of temperature and sex on the size of different cell types in the Madagascar ground gecko Paroedura picta. Biol Open 6:1149-1154

Falconi R, Renzulli T, Zaccanti F (2006) Survival and reproduction in Aeolosoma viride (Annelida, Aphanoneura). Hydrobiologia 564: 95-99
Ghalambor CK, Martin LB, Woods HA (2015) Plasticity, complexity, and the individual integrative organismal biology. John Wiley \& Sons Inc, Hoboken

Gregory TR, Hebert PDN (1999) The modulation of DNA content: proximate causes and ultimate consequences. Genome Res 9:317-324

Gregory TR, Hebert PDN, Kolasa J (2000) Evolutionary implications of the relationship between genome size and body size in flatworms and copepods. Heredity 84:201-208. https://doi.org/10.1046/j. 1365-2540.2000.00661.x

Hessen DO (2015) Noncoding DNA as a phenotypic driver. Evol Biol 42: 427-431. https://doi.org/10.1007/s11692-015-9335-6

Hessen DO, Daufresne M, Leinaas HP (2013) Temperature-size relations from the cellular-genomic perspective. Biol Rev 88:476-489. https://doi.org/10.1111/brv.12006

Hessen DO, Persson J (2009) Genome size as a determinant of growth and life-history traits in crustaceans. Biol J Linn Soc 98:393-399

Inamori Y, Kuniyasu Y, Hayashi N, Ohtake H, Sudo R (1990) Monoxenic and mixed cultures of the small metazoa Philodina erythrophthalma and Aeolosoma hemprichi isolated from a waste-water treatment process. Appl Microbiol Biotechnol 34:404-407

Jacques E, Verbelen JP, Vissenberg K (2013) Mechanical stress in Arabidopsis leaves orients microtubules in a "continuous" supracellular pattern. BMC Plant Biol 13:163. https://doi.org/10. 1186/1471-2229-13-163

Jalal M, Andersen T, Hessen DO (2015) Temperature and developmental responses of body and cell size in Drosophila; effects of polyploidy and genome configuration. J Therm Biol 51:1-14. https://doi.org/ 10.1016/j.jtherbio.2015.02.011

Jalal M, Wojewodzic MW, Laane CMM, Hessen DO (2013) Larger Daphnia at lower temperature: a role for cell size and genome configuration? Genome 56:512-520. https://doi.org/10.1139/gen-20130004

Jeffery NW, Yampolsky L, Gregory TR (2017) Nuclear DNA content correlates with depth, body size, and diversification rate in amphipod crustaceans from ancient Lake Baikal, Russia. Genome 60:303309. https://doi.org/10.1139/gen-2016-0128

Kiełbasa A, Walczyńska A, Fiałkowska E, Pajdak-Stós A, Kozłowski J (2014) Seasonal changes in the body size of two rotifer species living in activated sludge follow the temperature-size rule. Ecol Evol 4:4678-4689. https://doi.org/10.1002/ece3.1292

Kozłowski J, Czarnoleski M, Dańko M (2004) Can optimal resource allocation models explain why ectotherms grow larger in cold? Integr. Comp. Biol. 44:480-493

Kozłowski J, Konarzewski M, Gawelczyk AT (2003) Cell size as a link between noncoding DNA and metabolic rate scaling proceedings of the National Academy of Sciences USA 100:14080-14085 doi: https://doi.org/10.1073/pnas.2334605100

Lampert W (2006) Daphnia: model herbivore, predator and prey. Pol J Ecol 54:607-620

Leinaas HP, Jalal M, Gabrielsen TM, Hessen DO (2016) Inter- and intraspecific variation in body- and genome size in calanoid copepods from temperate and arctic waters. Ecol Evol 6:5585-5595. https:// doi.org/10.1002/ece3.2302

Maciak S, Bonda-Ostaszewska E, Czarnoleski M, Konarzewski M, Kozlowski J (2014) Mice divergently selected for high and low basal metabolic rates evolved different cell size and organ mass. J Evol Biol 27:478-487

Menniti A, Morgenroth E (2010) The influence of aeration intensity on predation and EPS production in membrane bioreactors. Water Res 44:2541-2553. https://doi.org/10.1016/j.watres.2009.12.024

Rasch EM, Wyngaard GA (2006) Genome sizes of cyclopoid copepods (Crustacea): evidence of evolutionary constraint. Biol J Linn Soc 87: 625-635. https://doi.org/10.1111/j.1095-8312.2006.00610.x

Ratsak CH, Verkuijlen J (2006) Sludge reduction by predatory activity of aquatic oligochaetes in wastewater treatment plants: science or 
fiction? A review. Hydrobiologia 564:197-211. https://oi.org/10. 1007/s10750-005-1719-7

Rees DJ, Dufresne F, Glemet H, Belzile C (2007) Amphipod genome sizes: first estimates for Arctic species reveal genomic giants. Genome 50:151-158. https://doi.org/10.1139/g06-155

Sawicki W, Malejczyk J (2012) Histologia. Wydawnictwo Lekarskie PZWL, Warsaw

Schlegel A, Stainier DYR (2007) Lessons from "lower" organisms: what worms, flies, and zebrafish can teach us about human energy metabolism. PLoS Genet 3:2037-2048. https://doi.org/10.1371/ journal.pgen.0030199

StatSoft I (2014) STATISTICA (data analysis software system), 12 edn. StatSoft, Hamburg

Suzuki R, Shimizu Y, Ebie Y, Inamori Y, Sudo R (2005) Growth characteristics of small aquatic oligochaetes contributing on sludge reduction in biological wastewater treatment system. Jpn J Water Treatment Biol 41:121-128

Szarski H (1983) Cell size and the concept of wasteful and frugal evolutionary strategies. J Theor Biol 105:201-209

Verberk WCEP, Bilton DT, Calosi P, Spicer JI (2011) Oxygen supply in aquatic ectotherms: partial pressure and solubility together explain biodiversity and size patterns. Ecology 92:1565-1572

Waddington CH (1942) Canalization of development and the inheritance of acquired characters. Nature 150(3811):563-565

Walczyńska A, Kiełbasa A, Sobczyk M (2016) "Optimal thermal range" in ectotherms: defining criteria for tests of the temperature-size rule. J Therm Biol 60:41-48. https://doi.org/10.1016/j.jtherbio.2016.06. 006

Walczyńska A, Labecka AM, Sobczyk M, Czarnoleski M, Kozłowski J (2015a) The temperature-size rule in Lecane inermis (Rotifera) is adaptive and driven by nuclei size adjustment to temperature. $\mathrm{J}$ Therm Biol 54:78-85

Walczyńska A, Sobczyk $\_$(2017) The underestimated role of temperature-oxygen relationship in large-scale studies on size-totemperature response. Ecol Evol 7: 7434-7441. doi: https://doi.org/ 10.1002/ece3.3263

Walczyńska A, Sobczyk M, Czarnoleski M, Kozłowski J (2015b) The temperature-size rule in a rotifer is determined by the mother and at the egg stage. Evol Ecol 29:525-536

Woods HA (1999) Egg-mass size cell size: effects of temperature on oxygen distribution. Am Zool 39:244-252

Woods HA (2014) Mosaic physiology from developmental noise: withinorganism physiological diversity as an alternative to phenotypic plasticity and phenotypic flexibility. J Exp Biol 217:35-45. https:// doi.org/10.1242/jeb.089698

Woods HA, Makino W, Cotner JB, Hobbie SE, Harrison JF, Acharya K, Elser JJ (2003) Temperature and the chemical composition of poikilothermic organisms. Funct Ecol 17:237-245. https://doi.org/10. 1046/j.1365-2435.2003.00724.x

Woods HA, Wilson JK (2015) An elephant in the fog: unifying concepts of physiological stasis and change Integrative Organismal Biology

Xia XH (1995) Body-temperature, rate of biosynthesis, and evolution of genome size. Mol Biol Evol 12:834-842

Ye L, Wu J, Cohen P, Kazak L, Khandekar MJ, Jedrychowski MP, Zeng X, Gygi SP, Spiegelman BM (2013) Fat cells directly sense temperature to activate thermogenesis. Proc Natl Acad Sci U S A 110: 12480-12485. https://doi.org/10.1073/pnas.1310261110

Young B, Lowe JS, Stevens A, Heath JW (2006) Wheater's functional histology. Elsevier, New York 